\title{
DIABETIC MACULOPATHY DETECTION USING FUNDUS FLUORESCEIN ANGIOGRAM IMAGES - A REVIEW
}

\author{
Swapna T R $\mathbf{R}^{1}$, Chandan Chakraborty ${ }^{2}$ \\ ${ }^{1}$ Dept. of Computer Science and Engg, Amrita Vishwa Vidyapeetham, Coimbatore, Pin - 641112, India \\ ${ }^{2}$ School of Medical Science \& Technology, IIT Kharagpur, Pin-721302, West Bengal, India
}

\begin{abstract}
Computational retinal imaging and vision based techniques have been assisting ophthalmologists for efficient and rapid screening and diagnostics, like other healthcare areas. Human retina is the only place in the human circulatory systems that can be seen using non-invasive techniques like fundus imaging, Optical Coherence Tomography (OCT) and invasive technique like Fluorescein angiograms. Attempts have been progressing towards developing an automatic detection and analysis of many eye related complications like diabetic retinopathy; age-related macular degeneration and glaucoma. There have been many survey papers of algorithms for pre-processing, segmentation and classification involving Fundus and OCT images. It has been observed that fundus fluorescein angiograms (FFA) play an important role in the detection and analysis of diabetic maculopathy which has become one of the major complications arising due to prolonged diabetes. It is also considered as severe as it affects the central vision of the human eye. Here we propose to perform a systematic review of the developed algorithms for processing FFA images of patients suffering from diabetic maculopathy.
\end{abstract}

Keywords: Fluorescein angiogram; Diabetic Maculopathy, Segmentation, Enhancement and Quantification.

\section{INTRODUCTION}

Diabetes in India has become the most common disease. As per the WHO report [1], it is observed that there are $\sim 67$ million people with confirmed diabetes and another 30 million with pre-diabetes. Prolonged diabetes affects vision strength leading to a condition called diabetic retinopathy. Retinopathy has been the prominent cause of vision loss in India often called as the silent killer of vision. Similarly, diabetic maculopathy is a pathological condition that affects the macular region. In effect, it leads to central vision loss in the eye. Diabetic macular edema (DME) is another major reason for low vision and blindness mainly in diabetic population. Visual loss from DME is five times more than that from Proliferative Diabetic Retinopathy (PDR).The main modalities that are used for detection, classification and treatment of retinopathy are colour Fundus images, OCT and FFA images. Among these there had been many survey papers on the algorithms used for pre-processing, enhancement, segmentation, classification and quantification of different phases of retinopathy using colour Fundus images and OCT images but not in FFA images. FFA images are clinically used in the treatment of macular edema and they show with certainty the different stages of retinopathy and macular leakage in the cases associated with diabetic maculopathy. It was also found that they provide a good view of the retinal vessels which are not clearly visible in the associated colour fundus images [2].

Clinically FFA images affected with diabetic maculopathy can be classified into four types - focal, diffuse and ischemic maculopathy. Focal maculopathy is characterized by microaneurysms, hemorrhages, macular edema and hard exudates which are visualized as circular pattern. FFA image reveals leakages which are focal with adequate perfusion in the macular region. Diffuse maculopathy which consists of edema in the retinal region which are diffuse in nature. It is also characterized by posterior pole thickening with comparatively few hard exudates. Ischemic maculopathy is characterized by micro-vascular blockage [3].It is characterized by reduced vision with micro aneurysms, hemorrhages, existence or non-existence of macular edema with hard exudates which are less in number. FFA images shows non-perfusion areas which are associated with enlargement of Foveal Avascular Zone (FAZ) in preliminary stage and areas with capillary dropouts in middle stage and pre capillary arterioles in the advanced stage. 


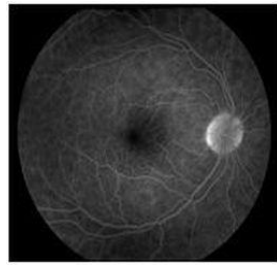

FFA of a normal eye

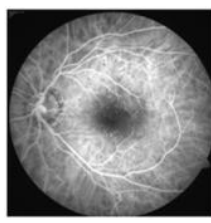

FFA images with focal leaks

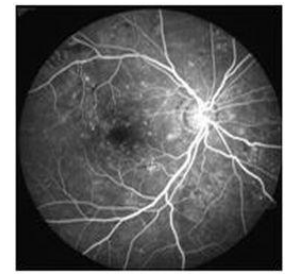

FFA with diabetic maculopathy

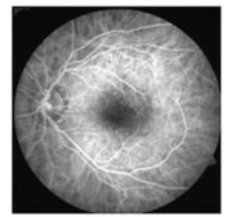

FFA images with diffuse leaks

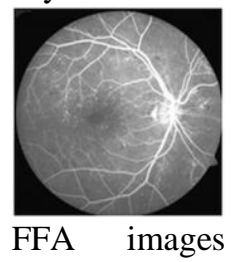

with ischemic leaks

\subsection{Survey Intentions}

The main goals of this survey are:

- To survey the literature over four decades in the field of diabetic maculopathy detection using FFA images.

- To give research scholars and educators with a detailed resource of the main algorithms employed in FFA analysis and quantification.

- To classify the literature into a series of stages.

- To identify relevant areas for further research.

Section 2 describes the resources used for the literature review. Section 3 identifies the potential steps needed for the development of a system for automatic detection of diabetic maculopathy. Section 4 provides a survey of the common image processing steps for detecting and quantification of diabetic maculopathy. The image processing operations for enhancing the FFA images, segmentation of the FAZ and quantification of diabetic maculopathy depending on the Early Treatment Diabetic Retinopathy Study (ETDRS) are discussed. We conclude in Section 5 by discussing recent trends and relevant areas for further research.

\section{SURVEY SCHEME}

The survey analyses and classifies the literature on the use of digital imaging techniques in diabetic maculopathy spanning four decades. The survey included data extraction from the internet and digital library of IIT Kharagpur and categorizing the data into basic image processing steps and involved a comparative study of various algorithms in a specific category of image processing step. The following bibliographic databases were searched: PubMed, IEEE Xplore Digital Library (IEEE), IEEE Transactions and Springer LNCS.This study included the use of different algorithms for detecting the normal and pathological retinal features associated with diabetic maculopathy in FFA images. Additional resources describing the algorithms applied were extracted from the reference lists of the reviewed articles. The extracted resources were classified according to the nature of image processing algorithm used. We also categorized the algorithms based on the methodology and its outcome. The existing resources for detection, analysis and classification of diabetic maculopathy and a brief explanation of the various image processing algorithm used are given in Section 4.

Though decades have passed, there were only limited numbers of papers in this area. The algorithms described in these papers were classified based on basic image processing steps which are essential for development of decision making system. The main subcategories are as follows:

A. Preprocessing - Contrast enhancement.

B. Segmenting the FAZ region.

C. Maculopathy quantification - identifying areas of macular leakage, micro aneurysms and hard exudates

\section{ENHANCEMENTS OF FLUORESCEIN}

\section{ANGIOGRAM IMAGES}

An early paper on contrast enhancement [4] talks about how enhancement can be done using Oral Fluorescein Angiogram images (OFA).This technique is currently applied to small children and old people for whom the intravenous access is not possible. Applying commonly used enhancement technique like histogram equalization had resulted in little change in the contrast since the important attribute of the retinal images has been the large distribution of the contrast within the FFA starting from the comparatively dark outer region of the FFA to the bright optic disc. This paper proposes a method called local contrast enhancement to overcome the problem with histogram equalization. This is based on the statistics of small areas within the image. This technique provided more contrast related to the mean and intensity of those particular small areas. If the local intensity variation is more, the algorithm maintains the contrast which is essential for preserving the retinal and pathological features associated with diabetic maculopathy. If the local intensity variation is small there is an increase in local contrast. For a thorough understanding of this algorithm and related mathematical concepts, readers are suggested to refer this paper [4]. The results indicate that the histogram equalization method increased the image contrast by $14.7 \%$ and the method suggested in this paper improved the image contrast by around $30 \%$.Most of the images enhanced by this algorithm were useful for the ophthalmologists compared to the images enhanced by histogram equalization which lead to only $58.3 \%$ of the images being clinically useful.

Table 1: Summarizes the various enhancement algorithms which are applied in Fundus and Angiogram images as a

\begin{tabular}{|l|l|l|l|}
\hline \multicolumn{4}{|c|}{ pre-processing step. } \\
\hline $\begin{array}{l}\text { Newsom et } \\
\text { al. (2000) }\end{array}$ & 12 & $\begin{array}{l}\text { Local } \\
\text { contrast } \\
\text { enhancement }\end{array}$ & $\begin{array}{l}\text { clinically useful } \\
\text { than histogram } \\
\text { based } \\
\text { enhancement }\end{array}$ \\
\hline
\end{tabular}




\section{SEGMENTATION OF FAZ}

\subsection{Genetic Snakes}

This early paper on medical image segmentation [5] used a contour model called snakes and suggested minimization of energy based on Genetic Algorithms to overcome problems of most optimization algorithms like initialization, getting stuck in the local minima and the exact selection of parameters for the model. Assuming that the FAZ is always positioned in the centre of the FFA, the position of the origin of the coordinates can be randomly selected by the user. To calculate the image energy both the magnitude and direction of the gradient and the Laplacian of Gaussian were considered. The internal energy controls the snake properties and the external energy was chosen based on the properties of the FAZ.

\subsection{Bayesian Method}

Segmentation of FFA images involved identifying the FAZ within the macular region. The paper [6] involved using a Bayesian network for detection of fovea, which is a part of the eye situated within the macular region. This paper modeled the foveal boundary by means of a onedimensional Markov chain and the intensities are assumed to be statistically independent and Gaussian. The model parameters are estimated by means of empirical and Bayesian methods. The foveal contour was estimated based on two approaches. They are simulated annealing (SA) and iterated conditional modes (ICM).

\subsection{Level-Set Based Segmentation}

The next approach on segmenting the FAZ was based on level-set method [7] [8] as it has been applied to many medical imaging applications and are popular for solving segmentation problems that are complex using powerful mathematical modeling. Instead of the traditional level-set method this paper has employed a variational level-set method [8] which was found to be more convenient and natural for combining information based on region and shapes into energy functional that are used in level set and which led to the production of more robust results. In this paper, they have assumed the level set function to be close to a signed distance function. The internal energy term calculates the error in the deviation of the level set function from a distance function. The external energy pulls the level-set to the object boundaries. The result is a gradient flow which minimizes the overall energy functional. But this technique requires the manual initialization for the segmentation program to start. Another paper [9] had applied a region-growing algorithm to detect the FAZ with minimum user intervention. The FAZ area that was calculated was smaller than that measured by doctors and the difference was statistically significant.
Table 2: Summarizes the various segmentation algorithms which are applied in Fundus Angiogram images for segmenting the FAZ.

\begin{tabular}{|l|l|l|l|}
\hline Authors & Method & Outcome & Remarks \\
\hline $\begin{array}{l}\text { Ballerini } \\
(1999)\end{array}$ & $\begin{array}{l}\text { Genetic } \\
\text { Snakes }\end{array}$ & $\begin{array}{l}\text { Local } \\
\text { minima and } \\
\text { selection of } \\
\text { parameters }\end{array}$ & $\begin{array}{l}\text { Quantitative } \\
\text { accuracy }\end{array}$ \\
\hline $\begin{array}{l}\text { Ibanez \& } \\
\text { Simo } \\
(1999)\end{array}$ & $\begin{array}{l}\text { Bayesian } \\
\text { statistical } \\
\text { method }\end{array}$ & $\begin{array}{l}\text { Fovea } \\
\text { contour } \\
\text { obtained by } \\
\text { ICM } \\
\text { responds to } \\
\text { intensity } \\
\text { changes }\end{array}$ & $\begin{array}{l}\text { Realistic } \\
\text { foveal } \\
\text { contours }\end{array}$ \\
\hline $\begin{array}{l}\text { Conrath } \\
\text { et al. } \\
\text { (2004) }\end{array}$ & $\begin{array}{l}\text { Region } \\
\text { growing in } \\
\text { semi- } \\
\text { automated } \\
\text { fashion }\end{array}$ & $\begin{array}{l}\text { FAZ area } \\
\text { was smaller } \\
\text { than that } \\
\text { measured by } \\
\text { clinicians }\end{array}$ & $\begin{array}{l}\text { The difference } \\
\text { of } \\
\text { measurements } \\
\text { was } \\
\text { statistically } \\
\text { significant. }\end{array}$ \\
\hline $\begin{array}{l}\text { Li et. Al. } \\
\text { (2005) }\end{array}$ & $\begin{array}{l}\text { Variational } \\
\text { Level-set }\end{array}$ & $\begin{array}{l}\text { 91\% of the } \\
\text { images } \\
\text { segmented } \\
\text { were } \\
\text { clinically } \\
\text { valid. }\end{array}$ & $\begin{array}{l}\text { To measure } \\
\text { the ischemic } \\
\text { zones in extra } \\
\text { macular area } \\
\text { of the fundus. }\end{array}$ \\
\hline
\end{tabular}

\section{QUANTIFICATION OF DIABETIC MACULOPATHY}

The need of quantifying the retinal pathological attributes of a disease is to monitor the progress of the disease, the quantification consists of object counting or measuring the area. Some have experimented with quantification using morphological analysis of Fluorescein Angiograms [10]. Semi-automated techniques for measuring the hard exudates are also present which requires human interventions [11][12],[13]. A method suggested in this paper for measuring the area of leakage has not found any applications [14]. A method suggested for identifying the macular leakage involves comparing two Fluorescein Angiogram images taken during different time frames after injecting the dye. The images are aligned and a gradient for intensity of both FFA images were calculated and ideal threshold value is chosen and the pixels whose value is less than this threshold is chosen as the spots of leakage [15]. For identifying the retinal exudates, a threshold based on the distribution of gray levels in the image is calculated [16]. The only user intervention is for marking the region of Interest in the image. Finally for identification and quantification of microaneurysms shade correction and shape operators are used within a macular area [17][18]. 
Table 3: Summarises the various Quantification algorithms which are applied in Fundus and Angiogram images

\begin{tabular}{|l|l|l|l|}
\hline Authors & Method & Outcome & Remarks \\
\hline $\begin{array}{l}\text { Baudoin et } \\
\text { al. (1984) }\end{array}$ & $\begin{array}{l}\text { Top-hat } \\
\text { transformation }\end{array}$ & $\begin{array}{l}\text { Microaneurys } \\
\text { mithin the } \\
\text { witht } \\
\text { fuzzy } \\
\text { boundaries } \\
\text { are the most } \\
\text { difficult to } \\
\text { extract. }\end{array}$ & $\begin{array}{l}\text { Automated } \\
\text { and manual } \\
\text { counting } \\
\text { has been } \\
\text { done. }\end{array}$ \\
\hline $\begin{array}{l}\text { Ward et al. } \\
\text { (1989) }\end{array}$ & $\begin{array}{l}\text { An exudates } \\
\text { map based on } \\
\text { the binary } \\
\text { image is } \\
\text { generated. }\end{array}$ & $\begin{array}{l}\text { It wased to } \\
\text { monitor the } \\
\text { response of } \\
\text { the object to } \\
\text { laser } \\
\text { treatment. }\end{array}$ & \\
\hline $\begin{array}{l}\text { Philips et } \\
\text { al. (1991) }\end{array}$ & $\begin{array}{l}\text { Intensity to } \\
\text { detect macular } \\
\text { leakage. } \\
\text { Matched } \\
\text { filtering and } \\
\text { shape } \\
\text { operators }\end{array}$ & & $\begin{array}{l}\text { Quality of } \\
\text { images was } \\
\text { poor. }\end{array}$ \\
\hline
\end{tabular}

\section{DISCUSSION}

A survey of algorithms for the enhancement, segmentation, and quantification of images affected by diabetic maculopathy are presented. Though Fluorescein Angiogram images has got some drawback like vomiting and nausea, it has been suggested in [3] that the Fluorescein Angiogram images showed with certainty the different kinds of macular leaks and very much needed for the classification of macular edema. On the other hand we could find only few algorithms that address Fluorescein Angiogram image analysis. All the algorithms developed for classification has been tested on colour fundus images database like MESSIDOR, STARE and DIARETDB1 as there is no standard database for Fluorescein Angiogram images. The need for developing a database of Fluorescein angiogram images is a desirable goal. The quantification of maculopathy also had very few papers which included few techniques which are semiautomated and one which is clinically non-applicable. In this paper [19] the Fluorescein Angiograms negatives were projected onto a matt and the image captured by a video camera. The image naturally had noise due to the room lighting, camera aperture and camera angle. It had been suggested that an improvement over the nature of image capture and advancement in image processing technologies will help in quantification of the disease to be successful. Another problem is not having a standard for quantification of the disease as it is definitely the clinician who has to validate the algorithms. The development of an effective screening tool for diabetic maculopathy which will help the ophthalmologists for complete analysis of the Fluorescein Angiograms images is also a highly desirable goal.

\section{CONCLUSION}

There have been many studies in the area of diabetic retinopathy using standard databases of coloured fundus images which are available online. This literature survey reviewed the algorithms that have been applied in the image processing domain for the detection, analysis and quantification of FFA images affected with diabetic maculopathy. The survey spanned four decades, extracted and analyzed the papers that have come in FFA images. In this paper, we have insisted on the development of FFA database as it is one of the important needs for developing a system for diagnosis and treatment of diabetic maculopathy one of the silent killers of vision.

\section{ACKNOWLEDGEMENTS}

The authors would like to Acknowledge Dr. Gopal S Pillai, Head, Department of Ophthalmology, Amrita Institute of Medical Sciences (AIMS), Kochi for providing valuable information about diabetic maculopathy.The digital resources needed for the survey were collected from the libraries of Indian Institute of Technology (IIT) Kharagpur. and Amrita School of Engineering. The authors acknowledge Dept. of Biotechnology for providing financial support (BT/PR14073/BID/07/320/2010, Dt.19-02-2013).

\section{REFERENCES}

[1]. WHO Report," Prevention of Blindness from Diabetes Mellitus", WHO Press. Geneva. Switzerland; 2006.

[2]. Mihaela Florescu, Adriana Stanila. (2013). The role of Fluorescein Angiography in Diagnosis and treatment of Diabetic Retinopathy. ACTA Medica Transilvanica.pp.275277.Available:http://www.amtsibiu.ro/Arhiva/2013/Nr3en/Florescu_en_pdf.pdf

[3]. Khurana, "Diseases of the Retina", in Comprehensive Ophthalmology, 4th ed., New Delhi, New Age International (P) Ltd,2007, pp. 261-262

[4]. Richard S B Newsom, Chanjira Sinthanayothin, James Boyce, Anthony G Casswell, Tom H Williamson. (2000). Clinical evaluation of local contrast enhancement for oral Fluorescein angiograms. Eye 2000. 14, pp.318-323. Available:http://www.ncbi.nlm.nih.gov/pubmed/11026992

[5]. Lucia Ballerini, "Genetic snakes for Medical Images Segmentation". in EvolASP'99 and EuroEcTel'99, SpringerVerlag Berlin Heidelberg, 1999, pp.59-73.

[6]. M V Ibanez and A Simo. (1999).Bayesian detection of the fovea in eye fundus angiographies. Pattern Recognition Letters. 20, pp.229-240.Available: http://www.siue.edu/ sumbaug/RetinalProjectPapers/Bayesi an $\% 20$ detection $\% 20$ of $\% 20$ the $\% 20$ fovea $\% 20$ in $\% 20$ eye $\% 20 \mathrm{f}$ undus\%20angiographies.pdf

[7]. Yalin Zheng,Jagdeep Singh Gandhi,Alexandros N Stagnos, Claudia Campo,Deborah M Broadbent,Smon $\mathrm{P}$ Harding.(2010).Automated Segmentation of Foveal Avascular Zone in Fundus Fluorescein Angiography.Investigative Ophthalmology and Visual Science.51,7.Available:http://www.iovs.org/content/51/7/36 53.full

[8]. Chunming Li, Chenyang Xu,Changfeng Gui,Martin D Fox, "Level set Evolution without Re-initialization: A New 
Variational Formulation" in .IEEE Computer Society Conference on Computer Vision and Pattern Recognition 2005, pp. 1063-6919.

[9]. Conrath J, Valat O, Giorgi R, Adel M, Raccah D, Meyer F, Ridings B., et al.Semi-automated detection of the foveal avascular zone in Fluorescein angiograms in diabetes mellitus.Clin Exp Ophthalmol.2006;34:119-123.Available: http://www.ncbi.nlm.nih.gov/pubmed/16626424

[10]. Baudoin CE Lay BJ, Klein JC. (1984).Automatic detection of micro aneurysms in diabetic fluorescein angiography. Rev Epid em et $S$ ante.32. pp. 25461.Available: http://www.ncbi.nlm.nih.gov/pubmed/6522738 [11]. Ward NP, Tomlinson S, Taylor CJ.(1989).Image analysis of fundus photographs. The detection and measurement of exudates associated with diabetic retinopathy. Ophthalmology. 96, pp.80-86.Available: http://www.aaojournal.org/article/S0161-

6420\%2889\%2932925-3/abstract?cc=y

[12]. Sleightholm MA, Arnold JV, Aldington SJ, Kohner EM.(1984).Computer aided digitization of fundus photographs.Clin Phys Physiol Meas. 5, pp. 295301.Available: http://iopscience.iop.org/0143-0815/5/4/005

[13]. Gilchrist J.(1987).Analysis of early diabetic retinopathy by computer processing of fundus images: - a preliminary study.Ophthal Physiol Opt.,7, pp. 393-399. Available: http://iopscience.iop.org/0143-0815/5/4/005.

[14]. Tamura S, Tanaka K, Hashi M et al.(1977).Analysis of fluorescence fundus angiographies. National Convention of I.P.S. J., pp. 673-674.

[15]. Phillips RP, Ross PGB, Tyszka M, Sharp PF, Forrester JV.Detection and quantification of hyper fluorescent leakage by computer Analysis of fundus fluorescein angiograms.(1991).Graefe's Arch Glin Exp Ophthalmol.,229,pp.329-335.Available:

http://www.nature.com/eye/journal/v5/n1/abs/eye199124a.ht $\mathrm{ml}$

[16]. Phillips RP, Ross PGB, Sharp PF, Forrester JV.Automated detection and quantification of retinal exudates.(1993). Am J Ophthalmol, 231, pp.9094. Available:

http://www.ncbi.nlm.nih.gov/pubmed/8444365

[17]Rosenfeld A,Kak AC,"Chapter 9" in Digital Picture Processing. Orlando,Academic Press, 1982.

[18]. Rosenfeld A and Kak AC,"Chapter 11" in Digital Picture Processing. Orlando, Academic Press, 1982.

[19]. R P Philips, T Spencer, P G B Ross F Sharp, J V Forrester.(1991).Quantification of Diabetic Maculopathy by Digital imaging of the Fundus..Eye, 5, pp.130-137.

\section{BIOGRAPHIES}

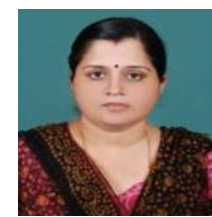

Swapna T R is an Assistant Professor in the Department of Computer Science \& Engineering, Amrita School of Engineering, Coimbatore and has an teaching experience of 13 years. She did her MTech from NIT-Calicut. She is currently pursuing her PhD from School of Medical Science and Technology (SMST), IIT Kharagpur. Her research interests are Medical imaging, Natural language processing and Machine Learning

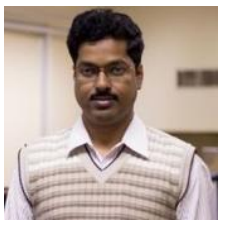

Dr. Chandan Chakraborty is currently an Associate Professor of School of Medical Science and Technology, IIT Kharagpur. His research interest includes computational medical imaging and informatics, pattern recognition and machine learning and statistical computing. He received various awards viz., DAE-Young Scientist Research Award (2013) IBM-SUR Awards (2011 \& 2013), IBM Faculty Award (2012), USA, and ISCA Young Scientist Award (2007). His research recognition is substantiated by more than 60 peer reviewed journal and 2 US patents and several conference articles. $\mathrm{He}$ is also a member of various professional bodies and editorial boards. 